https://doi.org/10.23913/ride.v11i22.855

Artículos científicos

\title{
La importancia de la lógica como base para el estudio de las matemáticas
}

\author{
The importance of Logic as a basis for study for mathematics \\ A importância da Lógica como base de estudo para a Matemática \\ Sérgio Brandão Defensor Menezes \\ Centro Territorial de Educação Profissional da Bacia do Paramirim, Brasil \\ sergiodefensor@yahoo.com.br \\ https://orcid.org/0000-0002-6053-0447
}

\section{Resumen}

El objetivo de este artículo es dar a conocer, a través de gráficos comparativos entre dos clases, la importancia de la lógica como base para el estudio de Matemáticas en el proceso de enseñanza-aprendizaje en el aula, con el fin de desarrollar una práctica docente innovadora. La investigación involucró las clases de 1er año A y B de bachillerato del Centro Territorial de Educación Profesional de la Cuenca DelParamirim, en la ciudad de Macaúbas - Bahía - Brasil. Los resultados obtenidos revelan un nuevo modelo didáctico con énfasis en la teoría lógica para entender los teoremas, axiomas, corolario y proposiciones matemáticas, así como identificar su importancia y mostrar que está directamente vinculado a todos los contenidos matemáticos. Finalmente, después de recopilar los datos y analizarlo, se puede recomendar que el profesor utilice esta innovadora metodología en los procesos de desarrollo de la enseñanza de las matemáticas, basado en los conceptos de la Lógica.

Palabras- Clave: Lógica, Matemáticas, Enseñanza. 


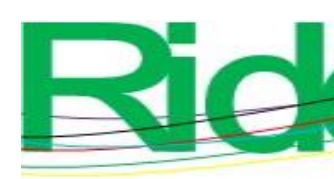

Revista Iberoamericana para la

Investigación y el Desarrollo Educativo

ISSN $2007-7467$

\section{Abstract}

The purpose of this article is to unveil, through comparative graphs between two classes, the importance of Logic as a basis for study for Mathematics in the classroom teachinglearning process, in order to develop an innovative teaching practicein order to develop an innovative teaching practice. The research involved the 1st year Classes A and B of the Territorial Center of Professional Education of the Paramirim Basin, in the city of Macaúbas- Bahia - Brazil. The results obtained reveal a new didactic teaching model with emphasis on logic theory for understanding the theorems, axioms, corollaries and mathematical propositions,as well as identify its importance and show that it is directly linked to all mathematical contents. Finally, after collecting the data and analyzing it, it can be recommended that the teacher use this innovative methodology in the processes of development of mathematics teaching, based on the concepts of Logic.

Keywords:Logic, Math, Teaching.

\section{Resumo}

O objetivo deste artigoédesvendar, através de gráficos comparativos entre duas turmas, a importância da Lógica como base de estudo para a Matemáticano processo de ensinoaprendizagem em sala de aula, a fim de desenvolver umaprática inovadora de ensino. A pesquisa envolveu as turmas do $1^{\circ}$ ano $\mathrm{A}$ e $\mathrm{B}$ do ensino médio do Centro Territorial de Educação Profissional da Bacia do Paramirim, na cidade de Macaúbas - Bahia - Brasil. Os resultados obtidos revelam um novo modelo didático de ensino com ênfase na teoria da Lógica para o entendimento dos teoremas, axiomas, corolários e proposições matemáticas, bem como identificam a sua importância e mostram que está diretamente ligada a todos os conteúdos Matemáticos. Por fim, após coletar os dados e analisá-los, pode-se recomendar que o professor utilize esta metodologiainovadoranosprocessos de desenvolvimento do ensino da matemática, baseada nos conceitos da Lógica.

Palavras-chave: Lógica, Matemática, Ensino.

Fecha Recepción: Junio2020

Fecha Aceptación:Enero 2021 


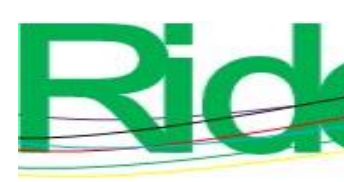

Revista Iberoamericana para la

Investigación y el Desarrollo Educativo ISSN $2007-7467$

\section{Introdução}

Este artigo mostra, através de gráficos comparativos entre duas turmas, a importância da Lógica como base de estudo para a Matemática no processo de ensinoaprendizagem em sala de aula. Esta pesquisa se deu a partir das deficiências dos alunos no entendimento dos conteúdos matemáticos. A cada aula, percebia-se que eles não compreendiam os teoremas, os axiomas, corolários e as proposições matemáticas. Houve a necessidade de incluir os conceitos da Lógica para que o entendimento dos conteúdos fosse alcançado.

O objetivo deste artigo é desvendar, através de gráficos comparativos entre duas turmas, a importância da Lógica como base de estudo para a Matemática no processo de ensino-aprendizagem em sala de aula.Afinalidade desse comparativo entre as duas turmas foi verificar o nível de desenvolvimento da turma $\mathrm{A}$ em relação à turma $\mathrm{B}$.

A justificativa é que: o conhecimento evolui progressivamente, por meio de estruturas de raciocínio que substituem umas às outras, através de estágios (Piaget, 1975). Isto significa que a lógica e as formas de pensar de uma criança são completamente diferentes da lógica dos adultos. Em sua Teoria, Piaget identifica os estágios de desenvolvimento da criança, sendo que, o ensino da lógica deve ser tratado nas primeiras fases da aprendizagem, principalmente, ao iniciar o ensino médio, onde os alunos devam aprender a desenvolver o raciocínio lógico para auxiliar na resolução de problemas; afim de que se tenha um maior incremento dos conteúdos matemáticos.

A motivação do autor para escrever esse artigo foi porque, praticamente, não se encontrar o conteúdo de Lógica nos livros didáticos atuais como base para o estudo da Matemática. Daí, a importância do resultado dessa pesquisa para que se tenha um apoio nesse sentido e, consequentemente, a efetiva aplicação dessa ferramenta.

\section{O Ensino da Lógica}

O ensino da lógica faz com que o pensamento matemático se desenvolva de maneira correta a fim de chegar a conhecimentos válidos. $\mathrm{O}$ aprendizado da lógica auxilia os estudantes no raciocínio, na compreensão de conceitos básicos e os prepara para o entendimento do conteúdo de temas mais avançados (Abar, 2006). É comum encontrar alunos universitários com dificuldades para interpretar o que estão lendo, por não terem sido alfabetizados para entender o que está "por trás” daquilo que está escrito, ou seja, o 


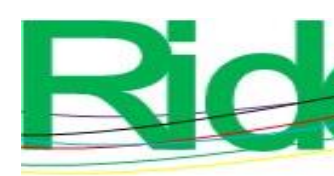

Revista Iberoamericana para la Investigación y el Desarrollo Educativo ISSN $2007-7467$

real significado e contexto (Rauber et al., 2003).

Este conteúdo da matemática é muito teórico, daí o desinteresse dos professores de matemática em trabalhá-lo, pois a grande maioria dos Matemáticos gosta de trabalhar a parte prática da matemática. Neste sentido, o ensino da matemática deixa a desejar. A partir de agora, será apresentado o conteúdo da Lógica aplicado no $1^{\circ}$ Ano, Turma A.

Algumas Definiçõos:

\section{Sentença}

Frase, expressão que encerra um sentido geral.

\section{Proposição}

Denomina-se proposição a toda sentença, expressa em palavras ou símbolos, que exprima um juízo ao qual se possa atribuir, dentro de certo contexto, somente um dos dois valores lógicos possíveis: verdadeiro ou falso.

Somente, as sentenças declarativas podem atribuir valores de verdadeiro ou falso, o que ocorre quando a sentença é, respectivamente, confirmada ou negada. Quando uma proposição é verdadeira, atribui-se o valor lógico V; quando ela é falsa, atribui-se o valor lógico F. Nota-se que não se pode atribuir valores de verdadeiro ou falso às outras formas de sentenças como as interrogativas, as exclamativas e as imperativas.

Alguns exemplos de Proposições:

- “O número 17 é ímpar.” - é uma declaração (afirmativa); portanto, uma proposição. Neste caso, tem-se uma proposição verdadeira (valor lógico V).

- “Todo ser humano é imortal” - é uma declaração (afirmativa); portanto, uma proposição. Neste caso, tem-se também uma proposição, mas agora falsa. (valor lógico F).

- “O Brasil não é um país.”-éumadeclaração(negativa);portanto,uma proposição. Neste caso, tem-se uma proposição falsa. (valor lógicoF).

- “O número 2 é primo" - é uma declaração (afirmativa); portanto, uma proposição verdadeira, ou seja, valor lógico V. 


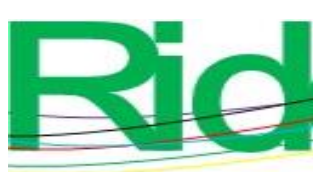

Revista Iberoamericana para la Investigación y el Desarrollo Educativo ISSN 2007 - 7467

Alguns exemplos de sentenças que não são proposições (sentenças abertas):

- “Qual sua cor preferida?” - é uma pergunta, e não uma declaração. Portanto, não é uma proposição. Não se pode atribuir a ela um valor lógico (V ouF).

- “Que bola feia!” - é uma sentença exclamativa, e não uma declaração. Portanto, não é uma proposição. Não se pode atribuir a ela um valor lógico (V ouF).

- “Paulo, vá fazer sua tarefa!" - é uma sentença imperativa, e não uma declaração. Portanto, não é uma proposição. Não se pode atribuir a ela um valor lógico (V ou F).

- “2 $2 x+25>50 ”$ - é uma sentença aberta,enãouma declaração. Portanto, não é uma proposição. Não se pode atribuir a ela um valor lógico (V ou F).

\section{Proposição simples}

Uma proposição é dita proposição simples ou operando quando apresenta apenas uma idéia.

Alguns exemplos:

- “Caio é estudioso".

- "Arthur é lindo".

- “Tatiana é uma mulher maravilhosa".

\section{Proposição composta}

Uma proposição é composta quando caracterizada por apresentar mais de uma proposição ligadas pelos conectivos lógicos.

Exemplo:

- João é irmão de Caio $e$ Maria é prima de Arthur.

- Maria é empresária $e$ Pedro é Pedreiro

\section{Conectivos lógicos}

Os conectivos lógicos agem sobre as proposições a que estão ligadas de modo a criar novas proposições. 
Tabela 1. Conceitos Lógicos

\begin{tabular}{|c|c|c|}
\hline $\begin{array}{c}\text { Estruturas } \\
\text { Fundamentais }\end{array}$ & Símbolos & Denominações \\
\hline A e B & $\wedge$ & Conjunção \\
\hline A ou B & $\vee$ & Disjunção \\
\hline Se A, então B & $\rightarrow$ & Condicional \\
\hline A se e somente se B & $\leftrightarrow$ & Bi condicional \\
\hline Ou A ou B & $\vee$ & DisjunçãoExclusiva \\
\hline Não A & $\sim$ & Negação \\
\hline
\end{tabular}

Fonte: Tabela elaborada pelo autor

Exemplo:

- A sentença "Se Caio não toma refrigerante, então Arthur vai jogar bola ou João toma suco". É uma proposição composta na qual se pode observar alguns conectivos lógicos ("não”, “se..., então” e “ou”) que estão agindo sobre as proposições simples "Caio não toma refrigerante", "Arthur vai jogar bola" e "João toma suco".

\section{Operações com proposições}

O valor lógico (verdadeiro ou falso) de uma proposição composta depende somente do valor lógico de cada uma de suas proposições componentes e da forma como estas sejam ligadas pelos conectivos lógicos utilizados.

Exemplo: 
Tabela 2. Valores Lógicos

\begin{tabular}{|l|c|}
\hline \multicolumn{1}{|c|}{ Proposições } & Valores Lógicos \\
\hline O número 2 é primo & Verdadeiro \\
\hline Peixesvoam & Falso \\
\hline $\begin{array}{l}\text { Todo número inteiro possui } \\
\text { inverso }\end{array}$ & Falso \\
\hline Todo número natural é inteiro & Verdadeiro \\
\hline
\end{tabular}

Fonte: Tabela elaborada pelo autor

\section{Definição dos conectivos}

\section{Conjunção: $(\wedge)$}

Representação: $(\mathrm{A} \wedge \mathrm{B}$ ). Lê-se: “A $e$ B”. Denomina-se conjunção a proposição composta formada por duas proposições quaisquer que estejam ligadas pelo conectivo "e".

Exemplos

- Dadas as proposições simples:

- $A$ : João é estudioso.

- $\quad B$ : Arthur é jogador de futebol.

- A conjunção “ $A$ e B” pode ser escrita como:

- $\quad(A \wedge B)$ : João é estudioso $e$ Arthur é jogador de futebol.

A conjunção é verdadeira, se e somente se, os operandos são verdadeiros.

Tabela 3. Conjunção

\begin{tabular}{|l|l|c|}
\hline $\mathrm{A}$ & $\mathrm{B}$ & $\mathrm{A} \wedge \mathrm{B}$ \\
\hline $\mathrm{V}$ & $\mathrm{V}$ & $V$ \\
\hline $\mathrm{V}$ & $\mathrm{F}$ & $F$ \\
\hline $\mathrm{F}$ & $\mathrm{V}$ & $F$ \\
\hline $\mathrm{F}$ & $\mathrm{F}$ & $F$ \\
\hline
\end{tabular}

Fonte: Tabela elaborada pelo autor 
Disjunção:( $\vee)$

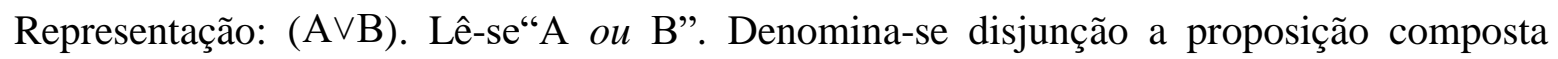
formada por duas proposições quaisquer que estejam ligadas pelo conectivo "ou”.

Exemplo:

- Dadas as proposições simples:

- A: Caio faz robótica.

○ $B$ : Tatiana é mãe de Arthur.

○ A disjunção “ $A$ ou $B$ ” pode ser escrita como:

○ $(A \vee B)$ : Caio faz robótica ou Tatiana é mãe de Arthur.

A disjunção é falsa, se e somente se, ambos os operandos forem falsos.

Tabela 4. Disjunção

\begin{tabular}{|l|l|c|}
\hline $\mathrm{A}$ & $\mathrm{B}$ & $\mathrm{A} \vee \mathrm{B}$ \\
\hline $\mathrm{V}$ & $\mathrm{V}$ & $V$ \\
\hline $\mathrm{V}$ & $\mathrm{F}$ & $V$ \\
\hline $\mathrm{F}$ & $\mathrm{V}$ & $V$ \\
\hline $\mathrm{F}$ & $\mathrm{F}$ & $F$ \\
\hline
\end{tabular}

Fonte: Tabela elaborada pelo autor

Disjunção exclusiva: $(\underline{\vee})$

Representação: (AㅌB). Lê-se: “ou A ou B”. Denomina-se disjunção exclusiva a proposição composta formada por duas proposições quaisquer em que cada uma delas esteja precedida pelo conectivo "ou".

Exemplo:

Dadas as proposições simples:

- A: O carro de César é prata.

- $B$ : O carro de César é preto.

- A disjunção exclusiva “ou A ou B” pode ser escrita como:

- $(A \underline{\vee} B): O u$ o carro de César é prata ou o carro de César é preto.

\section{(c) $(9$}




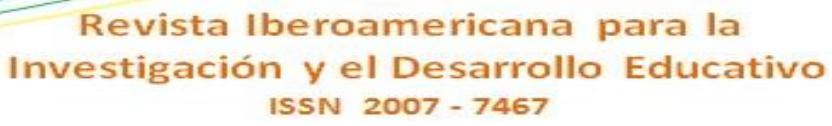

A disjunção exclusiva é verdadeira se, e somente se, apenas um dos operandos for verdadeiro.

Tabela 5. Disjunção Exclusiva

\begin{tabular}{|l|l|c|}
\hline $\mathrm{A}$ & $\mathrm{B}$ & $\mathrm{A} \underline{\vee} \quad \mathrm{B}$ \\
\hline $\mathrm{V}$ & $\mathrm{V}$ & $F$ \\
\hline $\mathrm{V}$ & $\mathrm{F}$ & $V$ \\
\hline $\mathrm{F}$ & $\mathrm{V}$ & $V$ \\
\hline $\mathrm{F}$ & $\mathrm{F}$ & $F$ \\
\hline
\end{tabular}

Fonte: Tabela elaborada pelo autor

Implicação (Condicional): $(\rightarrow)$

Representação: $(\mathrm{A} \rightarrow \mathrm{B})$. Lê-se: "Se A, então B". Denomina-se condicional a proposição composta formada por duas proposições quaisquer que estejam ligadas pelo conectivo "Se..., então".

Exemplo:

- Dadas as proposições simples:

○ $A$ : Juca é Macaubense.

○ B: Juca é Baiano.

○ A condicional "Se A, então B" pode ser escrita como:

○ $(A \rightarrow B)$ : Se Juca é Macaubense, então Juca éBaiano.

A condicional é falsa se, e somente se, o primeiro operando éverdadeiro e o segundo operando é falso. 
Tabela 06. Condicional

\begin{tabular}{|l|l|c|}
\hline $\mathrm{A}$ & $\mathrm{B}$ & $\mathrm{A} \rightarrow \mathrm{B}$ \\
\hline $\mathrm{V}$ & $\mathrm{V}$ & $V$ \\
\hline $\mathrm{V}$ & $\mathrm{F}$ & $F$ \\
\hline $\mathrm{F}$ & $\mathrm{V}$ & $V$ \\
\hline $\mathrm{F}$ & $\mathrm{F}$ & $V$ \\
\hline
\end{tabular}

Fonte: Tabela elaborada pelo autor

Dupla Implicação (Bi condicional): $(\leftrightarrow)$

Representação $(\mathrm{A} \leftrightarrow \mathrm{B})$. Lê-se: “A, se e somente se, B”. Denominamos bi condicional a proposição composta formada por duas proposições quaisquer que estejam ligadas pelo conectivo "se e somente se".

Exemplo:

- Dadas as proposições simples:

○ A: Pepinha é meu primo.

○ $B$ : Pepinha é filho de meus tios.

○ A bi condicional " $A$, se e somente se, $B$ " pode ser escrita como:

○ $(A \leftrightarrow B)$ : Pepinha é meu primo, se e somente se, Pepinha é filho de meus tios.

A bi condicional é verdadeira se, e somente se, os operandos têm o mesmo valor lógico.

Tabela 07. Bi condicional

\begin{tabular}{|l|l|c|}
\hline $\mathrm{A}$ & $\mathrm{B}$ & $\mathrm{A} \leftrightarrow \mathrm{B}$ \\
\hline $\mathrm{V}$ & $\mathrm{V}$ & $V$ \\
\hline $\mathrm{V}$ & $\mathrm{F}$ & $F$ \\
\hline $\mathrm{F}$ & $\mathrm{V}$ & $F$ \\
\hline $\mathrm{F}$ & $\mathrm{F}$ & $V$ \\
\hline
\end{tabular}

Fonte: Tabela elaborada pelo autor 


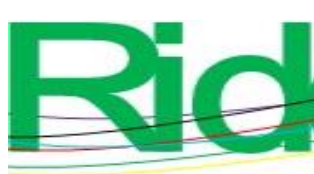

Negação:( )

Representação: $(\sim A)$. Lê-se: "Não A". Uma proposição é a negação de outra quando: se uma for verdadeira, então a outra é obrigatoriamente falsa e, se uma for falsa, então a outra é, obrigatoriamente, verdadeira.

Tabela 08. Negação

\begin{tabular}{|l|l|}
\hline $\mathrm{A}$ & $\sim \mathrm{A}$ \\
\hline $\mathrm{V}$ & $F$ \\
\hline $\mathrm{F}$ & $V$ \\
\hline
\end{tabular}

Fonte: Tabela elaborada pelo autor

Modos de Negação de uma Proposição Simples

Antepondo-se a expressão "não" ao seu verbo.

Exemplo:

- A: "Raul gosta de música".

○ A: "Raul não gosta de música".

Retirando-se a negação antes do verbo.

Exemplo:

- A: “João não é irmão de Maria”.

- A: "João é irmão de Maria".

Substituindo-se um termo da proposição por um de seus antônimos.

Exemplo:

- A: "x é um número positivo"

○ A: "x é um número negativo"

Observa-se que "A casa é branca" contradiz, mas não é a negação de "A casa é preta", porque a negação de "A casa não é branca" não, necessariamente, significa dizer que a cor da casa seja preta. Poderia ser de qualquer outra cor. 


\section{Tautologia}

Uma proposição composta é uma tautologia se ela for sempre verdadeira independentemente dos valores lógicos das proposições que a compõem.

Alguns exemplos

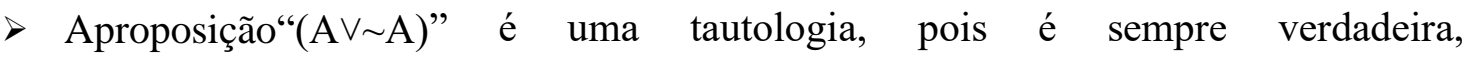
independentemente dos valores lógicos de A. Observe a tabelaa seguir:

Tabela 9. Tautologia

\begin{tabular}{|l|l|c|}
\hline $\mathrm{A}$ & $\sim \mathrm{A}$ & $\mathrm{A} \vee \sim \mathrm{A}$ \\
\hline $\mathrm{V}$ & $\mathrm{F}$ & $V$ \\
\hline $\mathrm{F}$ & $\mathrm{V}$ & $V$ \\
\hline
\end{tabular}

Fonte: Tabela elaborada pelo autor

\section{Contradição}

Uma proposição composta é uma contradição se ela for sempre falsa, independentemente, dos valores lógicos das proposições que as compõem.

\section{Exemplo}

> Aproposição“(A^ A)" é uma contradição, pois é sempre falsa, independentemente dos valores lógicos de A. Observe a tabela-verdade aseguir.

Tabela 10. Contadição

\begin{tabular}{|l|l|c|}
\hline $\mathrm{A}$ & $\sim \mathrm{A}$ & $\mathrm{A} \wedge \sim \mathrm{A}$ \\
\hline $\mathrm{V}$ & $\mathrm{F}$ & $F$ \\
\hline $\mathrm{F}$ & $\mathrm{V}$ & $F$ \\
\hline
\end{tabular}

Fonte: Tabela elaborada pelo autor

Nota-se que a negação de uma tautologia é sempre uma contradição.A negação de uma contradição é sempre uma tautologia. 


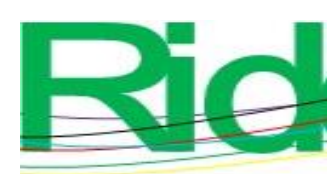

Revista Iberoamericana para la Investigación y el Desarrollo Educativo ISSN $2007-7467$

Equivalência: $(\Leftrightarrow)$

São proposições cujos valores lógicos são idênticos, independente dos valores dos operandos.Uma consequência prática da equivalência lógica é que, ao trocar uma dada proposição por qualquer outra que lhe seja equivalente, é como se estivesse apenas mudando a maneira de dizê-la.É importante lembrar que não se deve confundir o símbolo( $\Leftrightarrow$ ) da equivalênciade proposições com o símbolo $(\leftrightarrow)$ da bi condicional.

\section{Argumentos Lógicos}

Denomina-se argumento a relação que associa um conjunto de proposições $\mathrm{P}_{1}, \mathrm{P}_{2}$, $\ldots, \mathrm{P}_{\mathrm{n}}$, chamadas premissas do argumento, a uma proposição $\mathrm{C}$ a qual se chama de Conclusão.

$$
\{P 1, P 2, \ldots, P n\} \rightarrow C
$$

\section{Premissa}

Denomina-se Premissa a cada uma das proposições que serve de base para a conclusão. Quando se fala em premissas, não se deve discutir sua verdade ou falsidade, e nem se verificar a qual conclusão pode-se chegar através delas.

\section{Silogismo}

Argumento estruturado com três premissas. A primeira premissa denomina-se premissa maior, a segunda, premissa menor e a terceira, conclusão.

Exemplo

- Premissa 1: Todos os soldados são apaixonados.

○ Premissa 2: Todos os apaixonados gostam de chocolates.

○ Conclusão: Todos os soldados gostam de chocolates 


\section{Quanto à validade de um argumento \\ Argumento válido}

Diz-se que um argumento é válido ou, ainda, que ele é legítimo ou bem construído quando a sua conclusão é uma consequência obrigatória do seu conjunto de premissas; em outras palavras, quando um argumento é válido, a verdade das premissas deve garantir a verdade da conclusão do argumento.Isso significa que jamais se pode ter uma conclusão falsa quando as premissas forem verdadeiras e o argumento for válido.

É importante observar que o estudo dos argumentos não leva em conta a verdade ou a falsidade das proposições que compõem os argumentos, mas tão somente a validade destes. Desse modo, ao se discutir a validade de um argumento, o valor de verdade de cada uma de suas premissas é irrelevante.

Exemplo

- Considere o silogismo:

○ Premissa 1: Todos os cachorros são vegetarianos.

○ Premissa 2: Nenhum vegetariano gosta de brincar.

- Conclusão: Nenhum cachorro gosta de brincar.

Esse silogismo está perfeitamente bem construído, sendo, portanto, um argumento válido, muito embora a verdade das premissas seja questionável.

\section{Argumento inválido(falacioso)}

Diz-se que um argumento é inválido, também denominado ilegítimo, mal construído ou falacioso, quando a verdade das premissas não é suficiente para garantir a verdade da conclusão.

Exemplo

- Premissa 1: Todos os alunos do curso foram aprovados.

○ Premissa 2: Antônio não é aluno do curso.

○ Conclusão: Antônio foi reprovado.

É um argumento inválido, pois as premissas não garantem (não obrigam) a verdade da conclusão. Observa-se que Antônio pode ter sido aprovado sem ser aluno do curso. (A primeira premissa não afirmou que somente os alunos do curso foram aprovados). Nota-se 


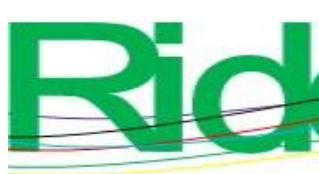

Revista Iberoamericana para la Investigación y el Desarrollo Educativo ISSN 2007 - 7467

que, geralmente, os problemas de silogismos apresentam expressões como "Todos", “Algum”, "Nenhum”. Muitos desses problemas são resolvidos mais facilmente com base na Teoria de Conjuntos e utilizando-se os Diagramas de conjuntos.

\section{Proposição Categórica}

Denomina-se Proposição Categórica a toda premissa que apresenta uma das seguintes estruturas:

- Todo A é B

- Algum A é B

- Algum A não é B

- Nenhum A é B

\section{Tabela - verdade}

Denomina-se tabela-verdade a um tipo de matemática usada em Lógica para determinar se uma fórmula éválida. Uma tabela verdade consiste em uma linha em que estão contidastodasassubfórmulas de uma fórmula.

Exemplo:

- Considere a equivalência: $\sim(\mathrm{p} \wedge \mathrm{q}) \Leftrightarrow \sim \mathrm{p} \vee \sim \mathrm{q}$

Usando a Tabela-Verdade e obtendo uma Tautologia, prova-se a sua equivalência. Veja:

Tabela 11.Tabela-verdade

\begin{tabular}{|l|l|c|c|c|c|c|c|}
\hline $\mathrm{p}$ & $\mathrm{Q}$ & $\sim \mathrm{p}$ & $\sim \mathrm{q}$ & $\mathrm{p} \wedge \mathrm{q}$ & $\sim(\mathrm{p} \wedge \mathrm{q})$ & $\sim \mathrm{p} \vee \sim \mathrm{q}$ & $\sim(\mathrm{p} \wedge \mathrm{q}) \leftrightarrow(\sim \mathrm{p} \vee \sim \mathrm{q})$ \\
\hline $\mathrm{V}$ & $\mathrm{V}$ & $\mathrm{F}$ & $\mathrm{F}$ & $\mathrm{V}$ & $F$ & $F$ & $\mathrm{~V}$ \\
\hline $\mathrm{V}$ & $\mathrm{F}$ & $\mathrm{F}$ & $\mathrm{V}$ & $\mathrm{F}$ & $V$ & $V$ & $\mathrm{~V}$ \\
\hline $\mathrm{F}$ & $\mathrm{V}$ & $\mathrm{V}$ & $\mathrm{F}$ & $\mathrm{F}$ & $V$ & $V$ & $\mathrm{~V}$ \\
\hline $\mathrm{F}$ & $\mathrm{F}$ & $\mathrm{V}$ & $\mathrm{V}$ & $\mathrm{F}$ & $V$ & $V$ & $\mathrm{~V}$ \\
\hline
\end{tabular}

Fonte: Tabela elaborada pelo autor 


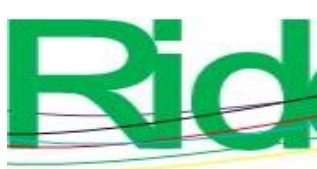

Revista Iberoamericana para la Investigación y el Desarrollo Educativo ISSN $2007-7467$

Observe que, independente, dos valores lógicos de p e q as tabelas verdades de $\sim(\mathrm{p} \wedge \mathrm{q})$ e $(\sim p \vee \sim q)$ são idênticas. Veja as colunas 6 e 7 da tabela-verdade acima. Ao fazer a bi condicional entre elas, obten-se a tautologia, como mostra a coluna 8. Neste caso, prova-se a sua equivalência.

Algumas equivalências importantes:

- $\sim(\mathrm{p} \wedge \mathrm{q}) \Leftrightarrow \sim \mathrm{p} \vee \sim \mathrm{q}$

- $\sim(\mathrm{p} \vee \mathrm{q}) \Leftrightarrow \sim \mathrm{p} \wedge \sim \mathrm{q}$

- $(\mathrm{p} \rightarrow \mathrm{q}) \Leftrightarrow \sim \mathrm{p} \vee \mathrm{q}$

- $(p \leftrightarrow q) \Leftrightarrow(p \rightarrow q) \wedge(q \rightarrow p)$

- $\sim(\sim p) \Leftrightarrow p$

\section{Quantificadores}

As expressões "Qualquer que seja”, “existe”, "para todo”, “algum”, “nenhum”... são chamadas de quantificadores.

Exemplo:

- Consideremos a sentença aberta

$P(x): x+1=3$.

A partir desta sentença podemos formar as seguintes proposições:

Existe $\mathrm{x}$ pertencente aos números inteiros; $\mathrm{x}+1=3$. ( Verdade )

Para todo $\mathrm{x}$ pertencente aos números inteiros; $\mathrm{x}+1 \neq 3$. (Falso).

Em ambos os casos, para $\mathrm{x}=2$, mostra a veracidade das respostas acima.

\section{Negação de Proposições com Quantificadores}

Os símbolos $\ni$ e $\forall$ têm uns significados bastante usados no dia-a-dia, mas, muitas vezes, as pessoas não se dão conta. Veja: 


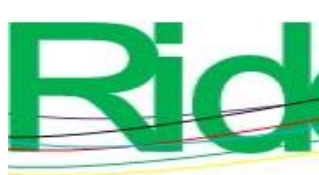

Revista Iberoamericana para la Investigación y el Desarrollo Educativo ISSN $2007-7467$

- $\quad \exists$ : Existe, pelo menos um, algum...

- $\quad \forall$ : Para todo, qualquer que seja, todo...

A negação do "Para todo" é "Existe" e vice versa. Neste caso, a negação da proposição com quantificadores, troca-se os quantificadores e muda a sentença.

Simbolicamente:

- $\sim(\exists \mathrm{x} ; \mathrm{P}(\mathrm{x})) \Leftrightarrow \forall ; \sim \mathrm{P}(\mathrm{x})$

- $\sim(\forall \mathrm{x} ; \mathrm{P}(\mathrm{x})) \Leftrightarrow \ni ; \sim \mathrm{P}(\mathrm{x})$

Exemplos:

- $\quad$ p:Todo número primo é ímpar. (Falso)

○ p:Existe um número primo que não é ímpar. (Verdadeiro)

- $\mathrm{q}$ :Existe $\mathrm{x}$ pertencente aos números inteiros, tal que $\mathrm{x}+1=9$. (Verdade)

○ $\sim \mathrm{q}:$ Para todo $\mathrm{x}$ pertencente aos números inteiros; $\mathrm{x}+1 \neq 9$. (Falso)

- $\quad r$ : Para todo x pertencente aos números inteiros; $x+1=5$. (Falso)

○ r: Existe $\mathrm{x}$ pertencente aos números inteiros; $\mathrm{x}+1 \neq 5$. (Verdade).

Nota-se que a negação de uma sentença verdadeira, torna-se falsa e a negação de uma sentença falsa, torna-se verdade.

Como já foi dito, o estudo da Lógica foi trabalhado apenas no $1^{\circ}$ ano do ensino médio do CETEP/BP, turma A. Enquanto a turma B estava tendo a revisão do ensino fundamental de acordo com a ementa feita pelo OCEM. Ao término do conteúdo de Lógica na turma $\mathrm{A}$ e a revisão na turma $\mathrm{B}$, o professor iniciou o conteúdo do ensino médio sugerido pelo OCEM em ambas as turmas. Os conteúdos trabalhados de agora em diantesãocomuns as duas turmas. São eles: Conjuntos Numéricos, Conjuntos e Funções. O ano letivo é dividido em três unidades. Naprimeiraunidade, trabalhou-se com Conjuntos Numéricos, que sãocoleções de números que possuem características semelhantes. Exemplo: Conjunto dos Números Naturais, quesurgiu da simples necessidade de se fazer contagens, por isso, seus elementos são apenas os números inteiros e não negativos. Sua representação é dada por

$$
\mathbb{N}=\{0,1,2,3,4,5,6,7,8,9,10,11, \ldots .\}
$$



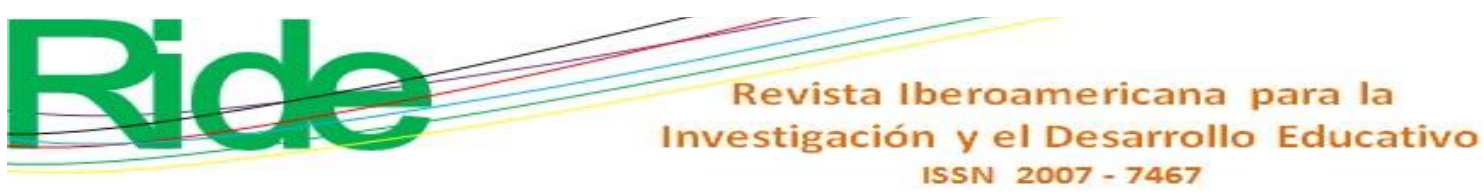

Na segunda unidade, o conteúdotrabalhadofoi Conjuntos, conteúdo que dá suporte aos Conjuntos Numéricos, como exemplo o Diagrama de Venn. Na teoria de conjuntos, as relações entre os Conjuntos Numéricos podem ser representadas da seguinte maneira:

Figura 1. Representação de conjuntos numéricos por meio do Diagrama de Venn

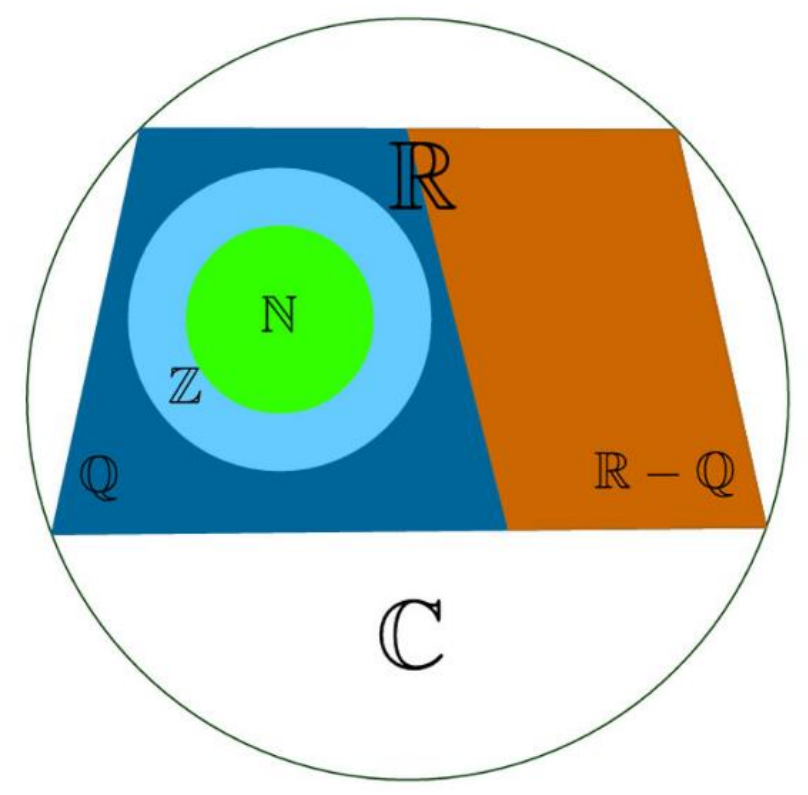

Fonte: https://brasilescola.uol.com.br/o-que-e/matematica/o-que-sao-conjuntosnumericos.htm

Por fim, na Terceira Unidade, trabalhou-se com Funções, conteúdo este que se trata de uma regra, onde se relaciona cada elemento de um conjunto (representado pela variável x) a um único elemento de outro conjunto (representado pela variável y). Ou seja, para cada valor de x, pode-se determinar um único valor de y, neste caso, diz-se então que "y está em função de x". Exemplo: 


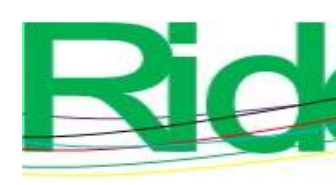

Figura 2. Diagrama de flechas usado para representar funções

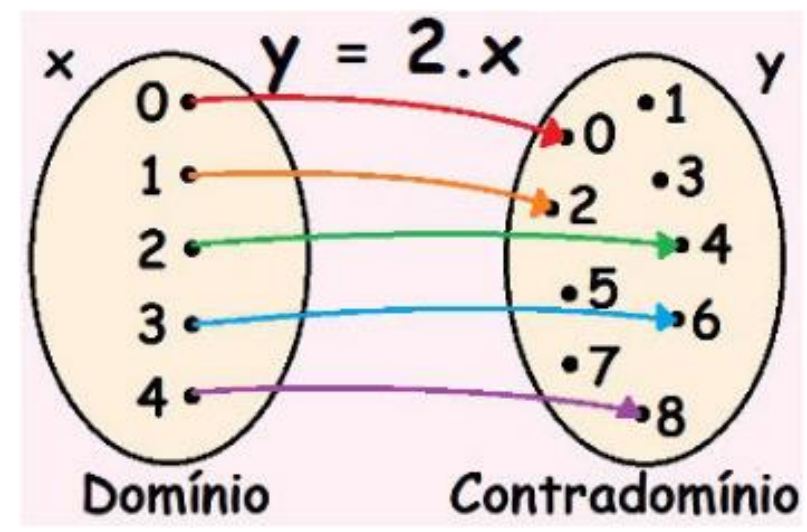

Fonte: https://brasilescola.uol.com.br/o-que-e/matematica/o-que-e-funcao.htm

Ao final de cada unidade, foi feita uma avaliação idêntica em cada unidade nas duas turmas. A evolução da Turma A em relação à Turma B será mostrada, conforme a Análise dos Dados a seguir.

\section{Metodologia}

A pesquisa envolveu as turmas do $1^{\circ}$ ano $\mathrm{A}$ e $\mathrm{B}$ do ensino médio do Centro Territorial de Educação Profissional da Bacia do Paramirim (CETEP/BP), na cidade de Macaúbas - Bahia - Brasil. A metodologia utilizada foi uma pesquisa quantitativa com análise e ênfase para seus aspectos analíticos e críticos através das avaliações nas turmas A e $\mathrm{B}$ do $1^{\circ}$ ano do ensino médio do CETEP/BP.A investigação é quantitativa e apresenta como objetivos a identificação e apresentação de dados, indicadores e tendências observáveis. Este tipo de investigação se mostra geralmente apropriado quando existe a possibilidade de recolha de medidas quantificáveis de variáveis e inferências a partir de amostras de uma população.O Método apresentado na experiência foi o estudo Longitudinal. O local da pesquisa foi nas salas de aula $n^{\circ} 5$ e 7 do CETEPBP, que é uma escola pública situada no centro da cidade de Macaúbas - Bahia - Brasil. Neste colégio, estudam aproximadamente 1500 alunos. Os recursos didáticos disponíveis eram quadros, projetores e computadores. A investigação foi centrada nas turmas supracitadas, que é composta por 32 alunos na Turma A e 30 Alunos na Turma B, com idade entre 15 a 19 anos. De acordo com as Orientações Curriculares para o Ensino Médio (OCEM), a Lógica não faz parte dos conteúdos matemáticos. No sentido de confrontar essa decisão, o autor decidiu comparar as duas turmas. No $1^{\circ}$ ano ensino médio A, aplicou-se o conteúdo de 


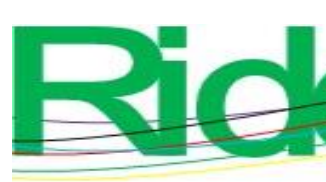

Revista Iberoamericana para la

Investigación y el Desarrollo Educativo

ISSN $2007-7467$

Lógica, antes de introduzir os conteúdos da OCEM; no $1^{\circ}$ ano ensino médio B, trabalhou-se seguindo as normas da escola, sem ver o conteúdo de Lógica, porém foi feita uma revisão do ensino fundamental, conforme sugere as Orientações Curriculares. Ao final de cada unidade, foram feitas duas avaliações idênticas, no mesmo horário, com o mesmo suporte; uma na turma A e outra na Turma B. Como as turmas A e B tinham números distintos de alunos, ou seja, 32 alunos na turma A e 30 alunos na Turma B, além de ser observada a distribuição das notas, também foram obtidas médias aritméticas das notas das duas turmas conforme gráficos, representados nas figuras de 03 a 10 na seção Resultados e Discussões.

\section{Resultados}

Nesta Análise de Dados, apresentam-se os gráficos das notas das duas turmas durante o ano letivo de 2019. Na primeira unidade, o conteúdo trabalhado nas duas turmas foi Conjuntos Numéricos; após concluí-lo, aplicou-se uma avaliação idêntica em cada turma. Assim procedeu com os demais conteúdos durante todo o ano letivo, sempre comparando as suas notas. Na segunda unidade, o conteúdo foi Conjuntos e, por fim, na terceira unidade, o conteúdo matemático foi Funções. Nas figuras de números 03 a 08 , observa-se a frequência das notas dos alunos por unidade.

Figura 3. Gráfico das notas da Turma A, Conjuntos Numéricos

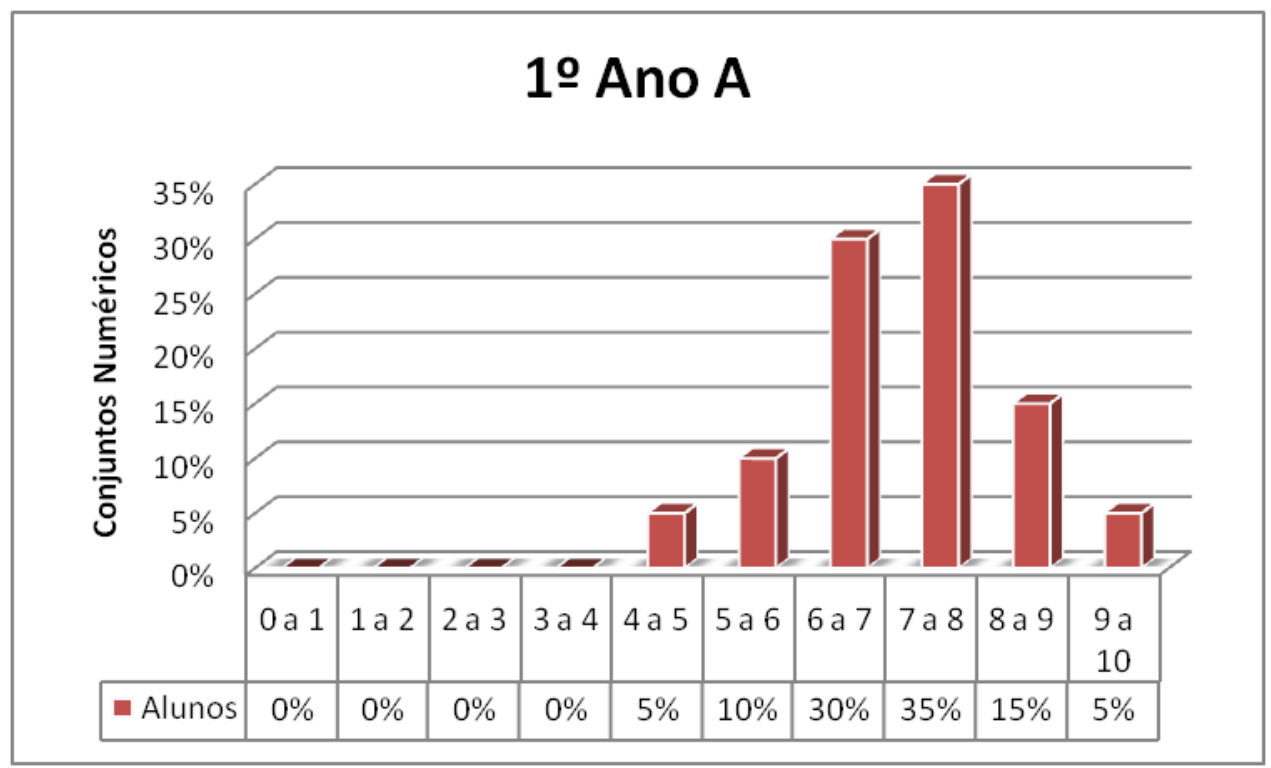

Fonte: Figura elaborada pelo autor 
Figura 4. Gráfico das Notas da Turma B, Conjuntos Numéricos

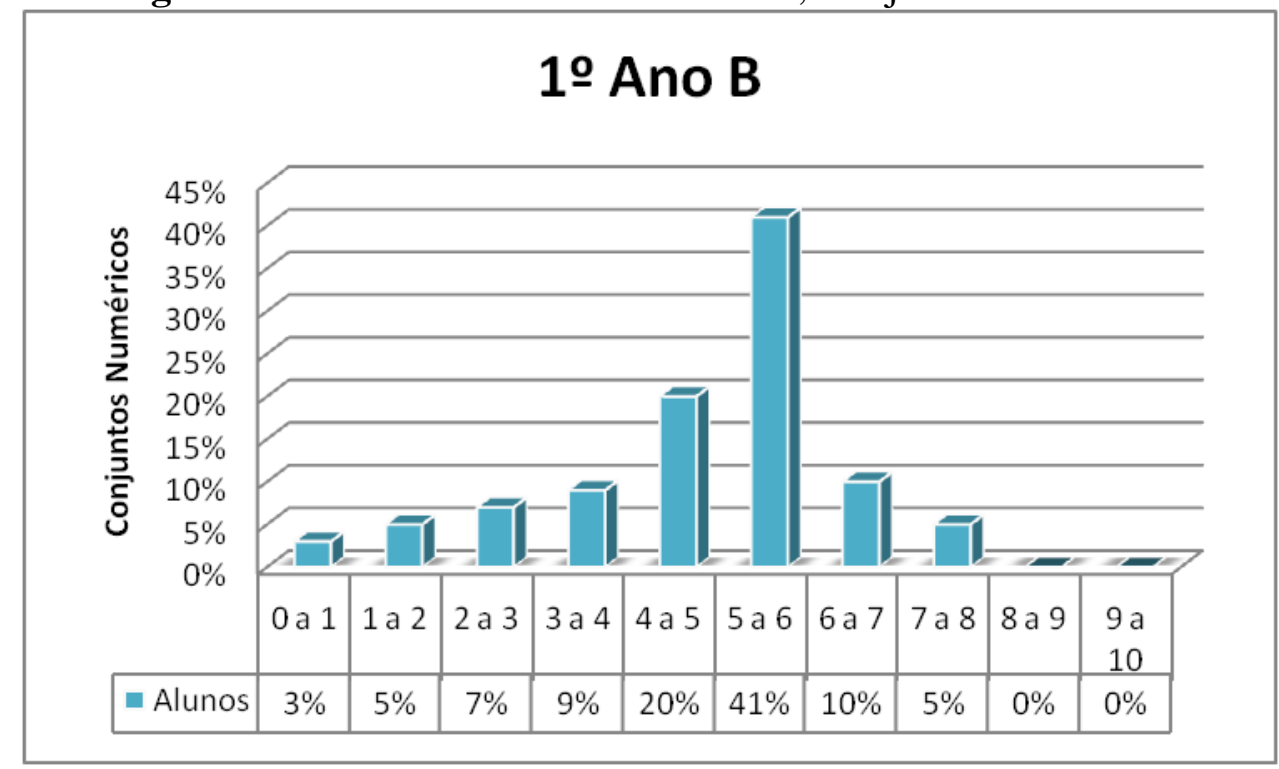

Fonte: Figura elaborada pelo autor

Figura 5. Gráfico das Notas da Turma A, Conjuntos

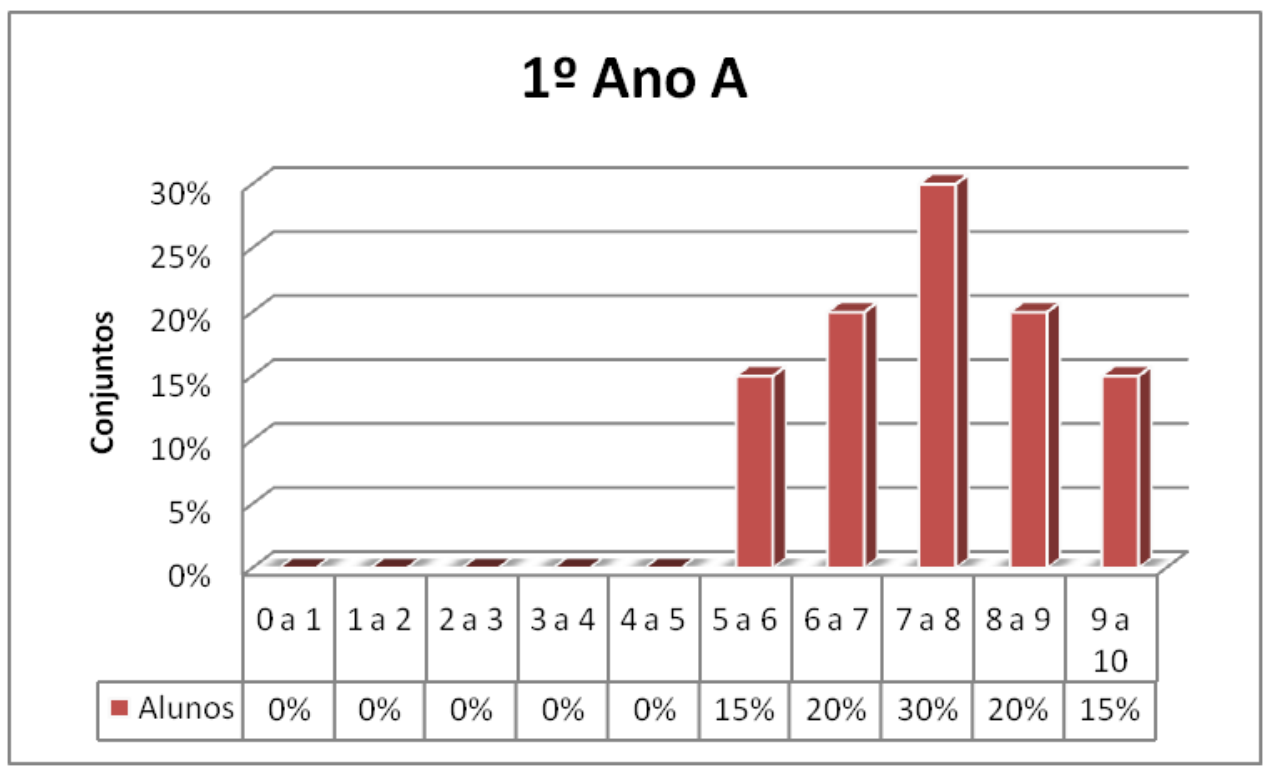

Fonte: Figura elaborada pelo autor 
Figura 6. - Gráfico das Notas da Turma B - Conjuntos

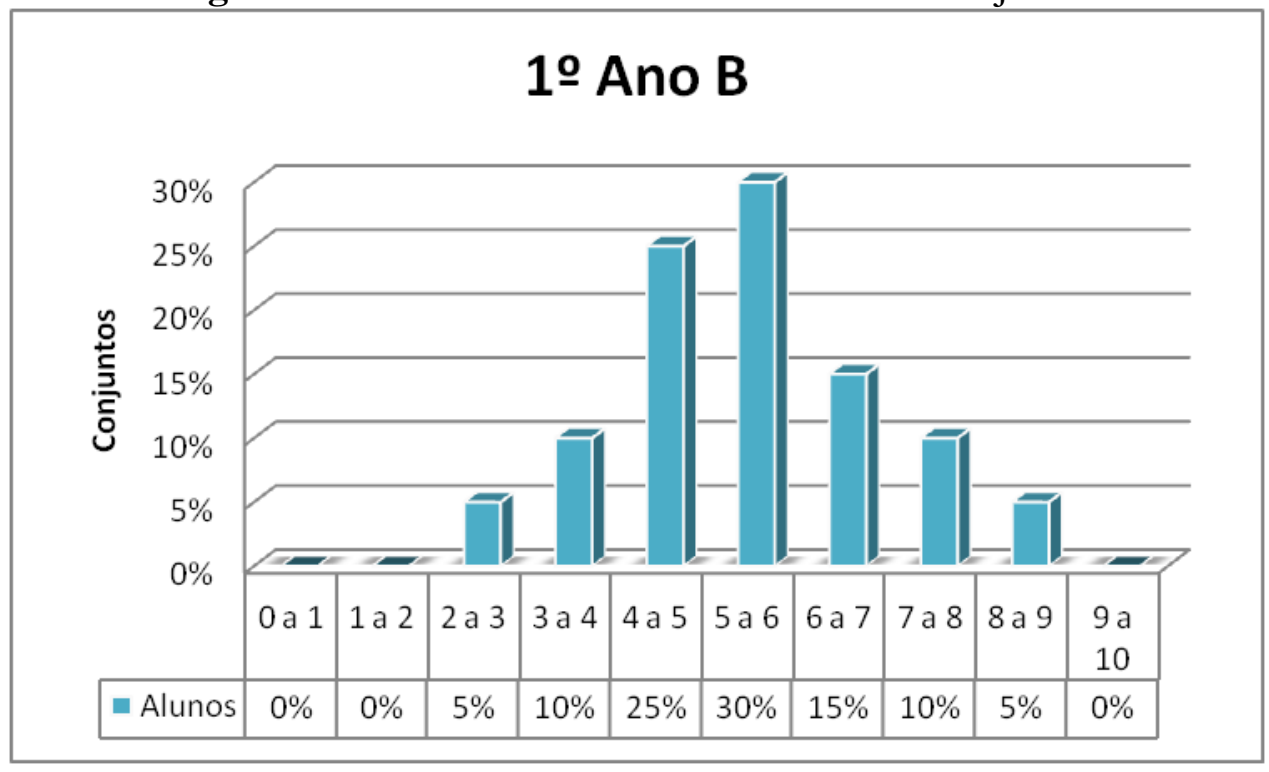

Fonte: Figura elaborada pelo autor

Figura 7. Gráfico das Notas da Turma A, Funções

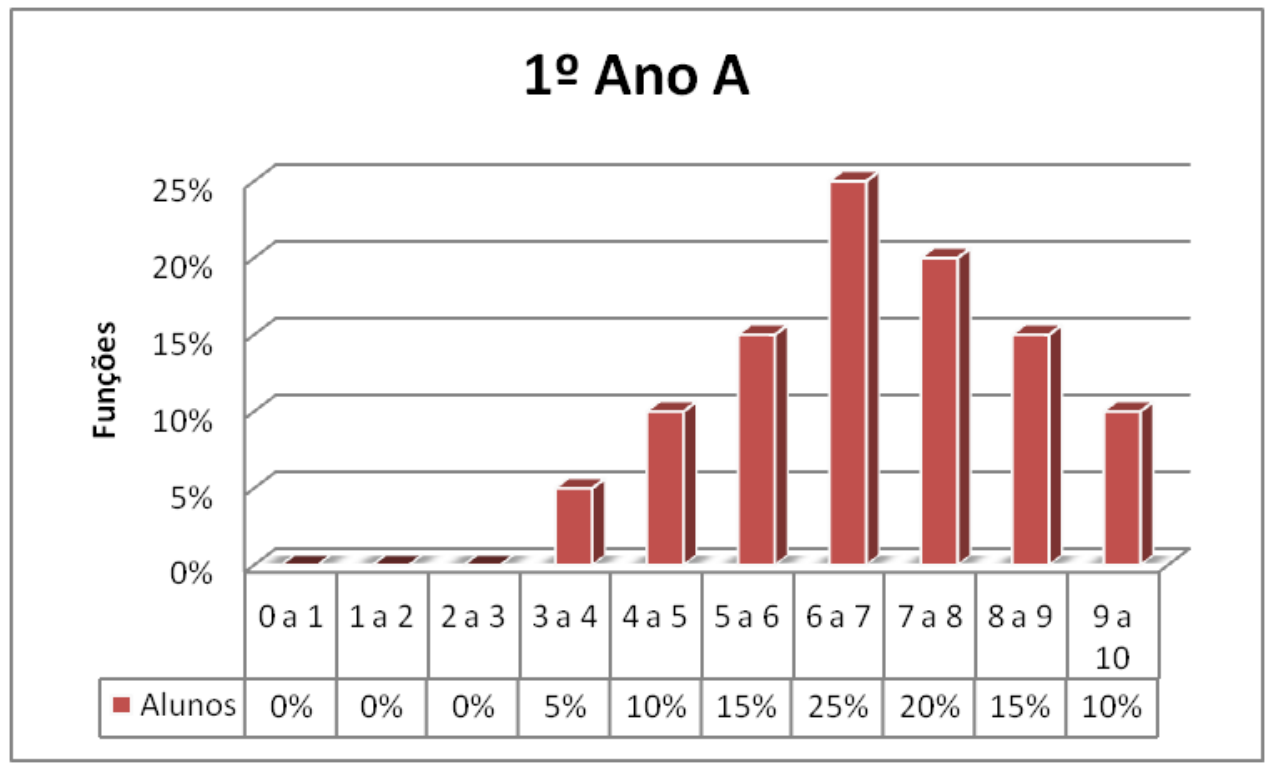

Fonte: Figura elaborada pelo autor 
Figura 8. Gráfico das Notas da Turma B, Funções

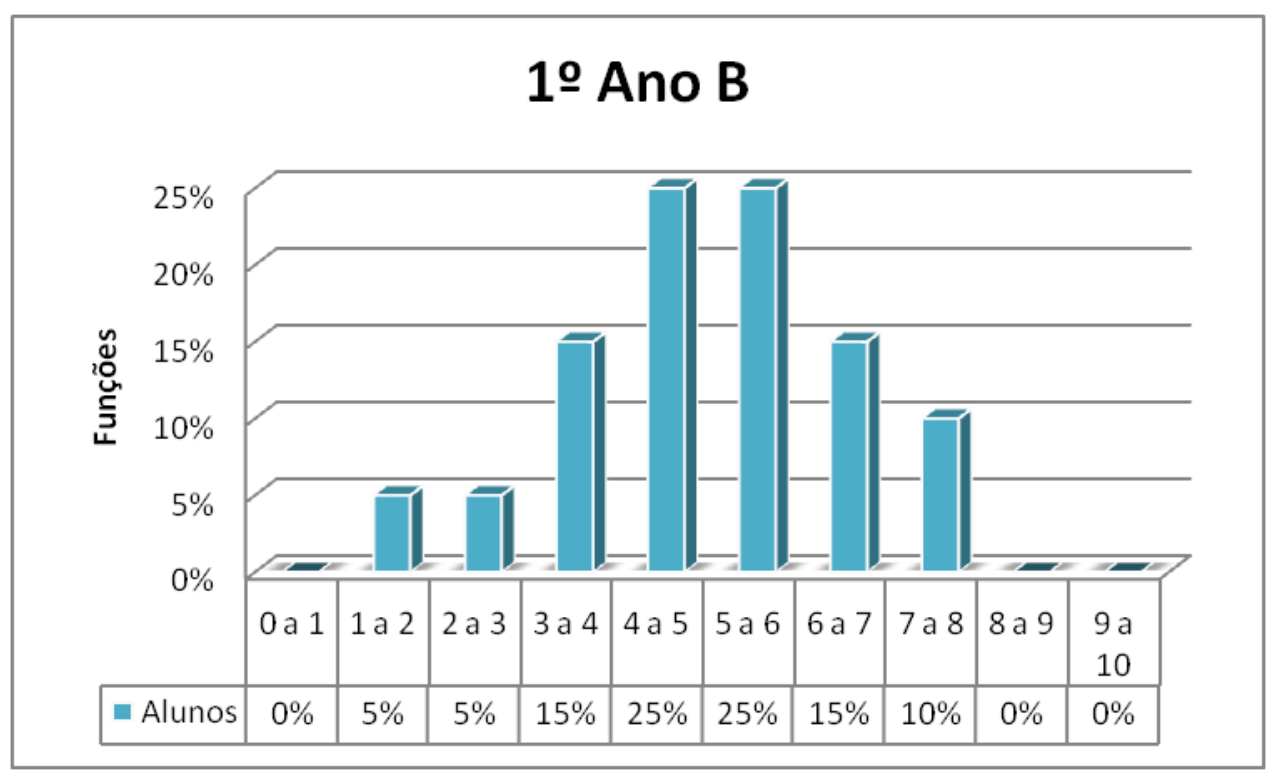

Fonte: Figura elaborada pelo autor

Abaixo, tem-se a figura 09, representando o gráfico comparativo entre as duas turmas. O primeiro ano A está representado pelas colunas vermelhas, enquanto a turma B está representada pelas colunas azuis. Nele, observa-se a distribuição do somatório das notas das três unidades (Conjuntos Numéricos, Conjuntos e Funções) de cada turma por classes de notas. Vale ressaltar que o total de cada turma, neste gráfico, chegará a 300\%, pois é a soma percentual das três unidades. Isso não tem relevância, pois o cálculo da média será feito posteriormente na figura 10. Analisando o gráfico, observa-se que a Turma A obteve os seguintes resultados: de $\mathbf{0 , 0}$ a 3,0,0\% dos alunos; de 3,1 a 4,0, $5 \%$ dos alunos; de 4,1 a 5,0, 15\% dos alunos; de 5,1 a 6,0, 40\% dos alunos; de 6,1 a 7,0, 75\% dos alunos; de 7,1 a 8,0, 85\% dos alunos; de 8,1 a 9,0, 50\% dos alunos; de 9,1 a 10,0, 30\% dos alunos.Já a turma B obteve: de $\mathbf{0 , 0}$ a 1,0, 3\% dos alunos; de 1,1 a 2,0, de 2,1 a 3,0, 10\% dos alunos; $17 \%$ dos alunos; de 3,1 a 4,0, 34\% dos alunos; de 4,1 a 5,0, 70\% dos alunos; de 5,1 a 6,0, 96\% dos alunos; de 6,1 a 7,0, 40\% dos alunos; de 7,1 a 8,0, 25\% dos alunos; de 8,1 a 9,0, $5 \%$ dos alunos; de $\mathbf{9 , 1}$ a $\mathbf{1 0 , 0}, 0 \%$ dos alunos. 
Figura 9. Gráfico comparativo do somatório das notas das turmas A e B

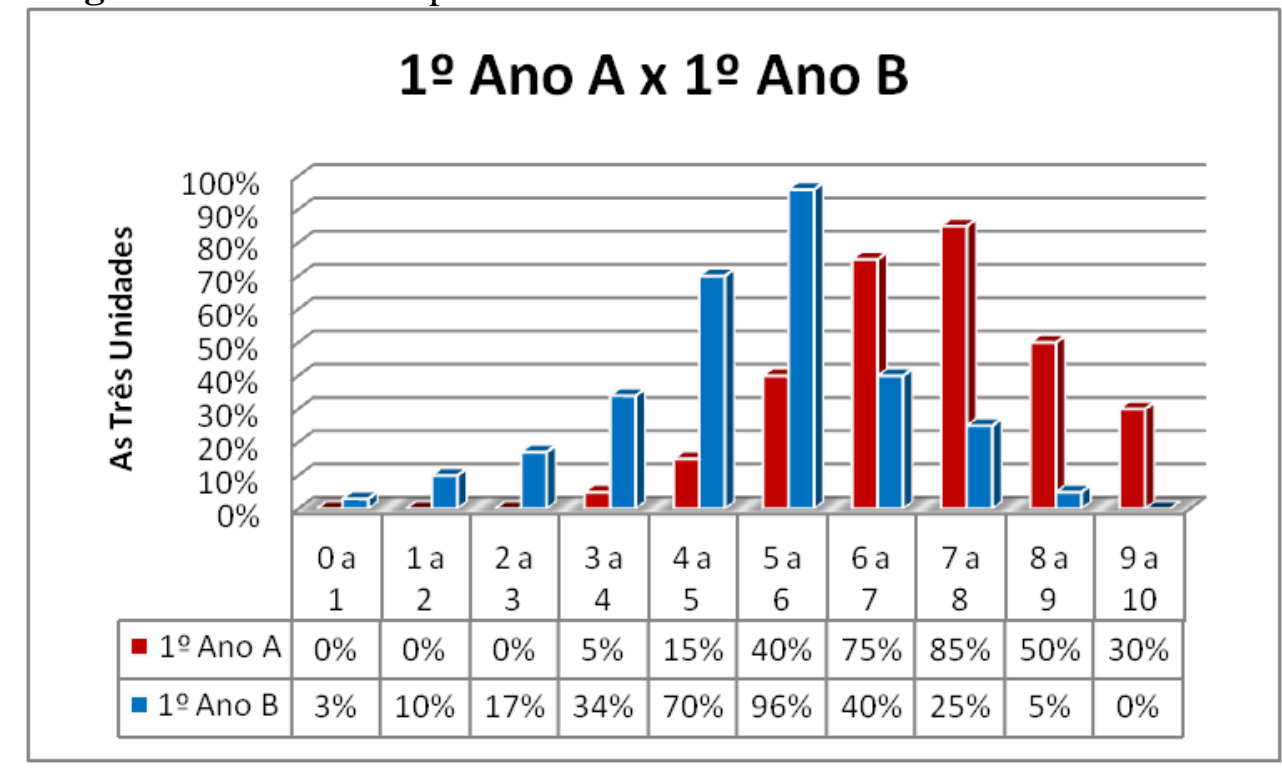

Fonte: Figura elaborada pelo autor

Abaixo, tem-se a figura 10, representando o gráfico comparativo entre as turmas $\mathrm{A}$ e B. Analogamente à figura anterior, o primeiro ano A está representado pelas colunas vermelhas, enquanto a turma B está representada pelas colunas azuis. Nele, observa-se a distribuição das médias ponderadas das notas das três unidades de cada turma por classes de notas. A fórmula da média ponderada usada é:

$\bar{X}$

$=\frac{0,5 \times f 1+1,5 \times f 2+2,5 \times f 3+3,5 \times f 4+4,5 \times f 5+5,5 \times f 6+6,5 \times f 7+7,5 \times f 8}{300 \%}$

Observe que $f i$, com $i$ variando de 1 a 10 se refere às freqüências percentuais das classes das notas e que os valores 0,$5 ; 1,5 ; 2,5 ; \ldots ; 9,5$ são as médias das classes das notas, respectivamente, de 0,0 a 1,$0 ; 1,0$ a 2,0;2,0 a 3,0; .. ; 9,0 a 10,0. Neste caso, tem-se:

A média da turma A é:

$\bar{X}=\frac{0,5 \times 0 \%+1,5 \times 0 \%+2,5 \times 0 \%+3,5 \times 5 \%+4,5 \times 15 \%+5,5 \times 40 \%+6,5 \times 75 \%+7,5 \times 85 \%+8,5 \times 50 \%+9,5 \times 30 \%}{300 \%}$

Usando números decimais e aproximando os valores:

$$
\bar{X}=\frac{0,0+0,0+0,0+0,18+0,68+2,2+4,88+6,38+4,25+2,85}{3}=\frac{21,4}{3}=7,13
$$




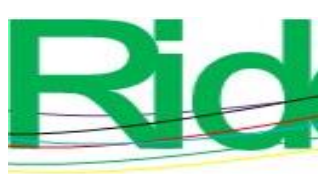

Revista Iberoamericana para la

Investigación y el Desarrollo Educativo

ISSN $2007-7467$

A média da turma B é:

$\bar{X}$

$=\frac{0,5 \times 3 \%+1,5 \times 10 \%+2,5 \times 17 \%+3,5 \times 34 \%+4,5 \times 70 \%+5,5 \times 96 \%+6,5 \times 40 \%+7,5 \times 25 \%+8,5 \times 5 \%+9,5 \times 0 \%}{300 \%}$

Usando números decimais e aproximando os valores:

$$
\begin{gathered}
\bar{X}=\frac{0,02+0,15+0,43+1,19+3,15+5,28+2,6+1,88+0,43+0,0}{3}=\frac{15,13}{3} \\
=5,04
\end{gathered}
$$

Figura 10. Gráfico da Média Geral

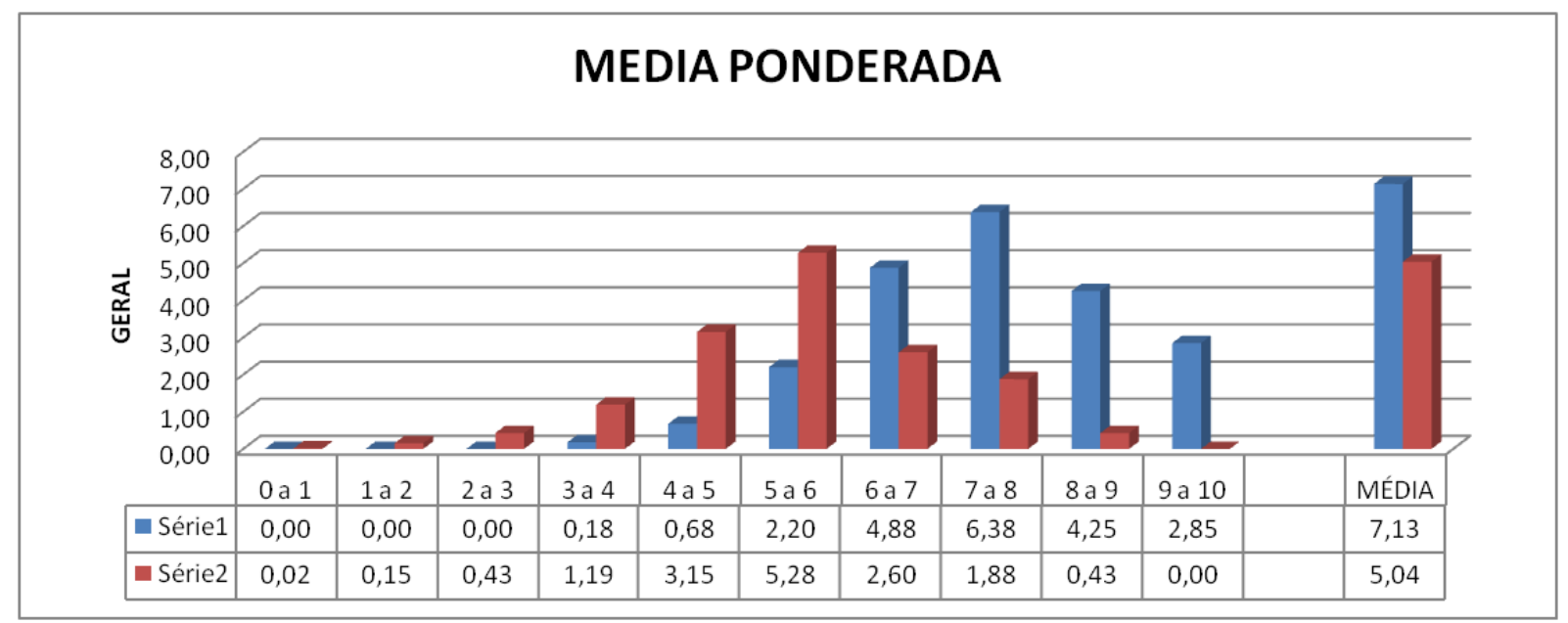

Fonte: Figura elaborada pelo autor

\section{Discussões}

Após a aplicação das três avaliações em cada turma sobre os conteúdos matemáticos trabalhados no ano letivo de 2019; os resultados estão representados pelos gráficos acima. Durante as aulas, o professor já havia percebido uma grande diferença na assimilação dos conteúdos;precisou usar um instrumento que medisse essa absorção dos conteúdos. Observa-se que a média das notas dos alunos da Turma A foi 7,13 numa escala de zero a dez, enquanto a média das notas dos alunos da turma B foi 5,04, o que confirma a necessidade de incluir a Lógica nos conteúdos de Matemática, como base na aprendizagem. $\mathrm{Na}$ medida em que o estudante adquire mais experiência da lógica, mais fatos lógicos serão considerados triviais por ele e maior será sua competência na lógica (Besson,2010). Nesse 


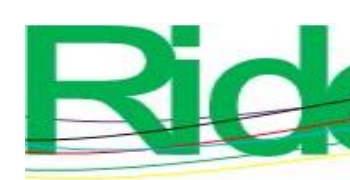

Revista Iberoamericana para la

Investigación y el Desarrollo Educativo

ISSN $2007-7467$

sentido, conhecer a lógica não deve se limitar à função de preservar a verdade e deduzir argumentos, mas elaborar o maior número possível de transformações (Corcoran, 1999).

\section{Conclusões e trabalho futuro}

Percebeu-se que, no decorrer desta pesquisa, a utilização da Lógica é um grande diferencial no entendimento dos conteúdos matemáticos, pois ela está implicitamente ligada a todos os conteúdos matemáticos, ajudando assim na aprendizagem. Também mostrou outro lado da matemática, que muitas vezes é desfavorecida por profissionais talvez sem preparação, não permitindo os estudantes presenciar os benefícios que nela existe. Os professores precisam demonstrar mais disposições em aplicar o uso da Lógica no ensino da matemática, pois utilizando esta ferramenta possibilita que as aulas de matemática se tornem mais interessantes.

Através da observação e durante as aulas de Lógica na Turma A, conseguiu-se detectar que os alunos desta Turma tiveram maisfacilidade em entender alguns conceitos matemáticos; diferentemente, da Turma B, pois, naquele momento, eles deixam transparecer suas reais dificuldades.

De acordo com o resultado obtido no último gráfico, representado pela figura 10 , houve uma grande diferença nas notas da turma A em relação à turma B. Esseresultado revela a importância de aplicar a teoria da Lógica para o entendimento dos teoremas, axiomas, corolários e proposições matemáticas, bem como identificam a sua importância e mostram que está diretamente ligada a todos os conteúdos Matemáticos.

Esta pesquisa foi de grande importância, devido ao problema que se tem na aprendizagem da matemática. O objetivo aqui foimostrar que a Lógica é, de fato, um conteúdo que deve ser usado como base para o entendimento da Matemática, consequentemente, incentivando os alunos a participarem mais das suas aulas. Percebeu-se que o alcance de resultados, submetidos a diversos recursos educacionais, inspeção e avaliação, os atuais educadores se encontram no centro de uma verdadeira encruzilhada: por um lado, cabe-lhes preservar os princípios educacionais inerentes à sua condição de educadores; por outro lado, são coagidos externamente a incorporar um perfil de professor obediente ao sistema, progressivamente, mais tecnocrático ao serviço dos valores da competitividade, do desempenho e dos resultados.Por fim, após coletar os dados e analisálos, recomenda-se que o professor utilize esta importante ferramenta como base de estudo 


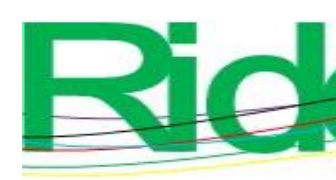

Revista Iberoamericana para la Investigación y el Desarrollo Educativo ISSN $2007-7467$

para Matemática.

Como um trabalho futuro, aLógica deve ser aplicada nos estudos iniciais da matemática, como forma de fortalecer a base do conteúdo matemático para o seu desenvolvimento de maneira mais eficaz.

\section{Referências}

Abar, C. (2006). Noções de Lógica Matemática. Disponível em: www.pucsp.br/ logica/ Bahia, Secretaria da Educação. (2015)Orientações curriculares para o ensino médio. área: matemática/ Secretaria da Educação. - Salvador: Secretaria da Educação, 32 p.: Il. Recuperado em http://escolas.educacao.ba.gov.br/orientacoescurricularesestaduais. Acesso: 09 de maio de 2020.

Besson, Corine; Bonelli, M; Longo, A. (2010) Quid Est Veritas?Essays in honour of Jonathan Barnes. Bibliopolis, Napoli.

Campos,Jaime Ferreira. (2001) Elementos de Lógica Matemática e Teoria dos Conjuntos, in Lições de Análise Real, Instituto Superior Técnico, Lisboa, Portugal.

Corcoran, John. (1999)Fragments of science. festschrift for Mendel Sachs. World Scientific Pub.CO. New York.

Imaguire, Guido; Barroso, Cícero A. C. (2006)Lógica: os jogos da razão. Ceará, Brasil. Universidade Federal do Ceará.

Menezes, Sérgio Brandão Defensor. (2014)Jogos Matemáticos: Aplicando em uma turma de um curso técnico em enfermagem. Dissertação de Mestrado, Matemática, Universidade Estadual do Sudoeste da Bahia, Vitória da Conquista, Brasil.

Menezes, Sérgio Brandão Defensor. (2016)Jogos Matemáticos: Estímulo e Aprendizagem. Tese de Doutorado, Ciências da Educação, UniversidadTecnológica Intercontinental, Assunção, Paraguai.

Mortari, C.A. (2016) Introdução à Lógica.Universidade Estadual Paulista. Ed. UNESP.São Paulo, Brasil.

Piaget, Jean. (1975). Gênese das estruturas lógicas elementares. Forense. Rio de Janeiro, Brasil.

Rauber, J; Rosseto, M; Fávero, A M; Fávero, A A; Tonieto, C. (2003). Que tal um pouco de lógica?!, Ed. Clio Livros, Passo Fundo, Brasil.

Ribeiro, Amanda Gonçalves. (2020)O que é função?. Brasil Escola. Disponível em: https://brasilescola.uol.com.br/o-que-e/matematica/o-que-e-funcao.htm. 


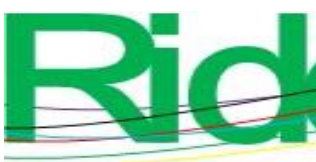

Acesso em 17 de novembro de 2020.

Salmon, W.C. (2010)Lógica. São Paulo, Brasil: LTC.

Silva, Luiz Paulo Moreira. (2020)O que são conjuntos numéricos?Brasil Escola. Disponível em: https://brasilescola.uol.com.br/o-que-e/matematica/o-que-saoconjuntos-numericos.htm. Acesso: 17 de novembro de 2020. 